\title{
Attributes of turnaround rural hospitals: Case study findings and research opportunities
}

\author{
Asa B. Wilson* \\ Health Administration Division, Central Michigan University, Mt. Pleasant, Michigan, United States
}

Received: July 18, 2017

DOI: $10.5430 /$ jha.v6n6p8
Accepted: October 3, $2017 \quad$ Online Published: October 20, 2017

URL: https://doi.org/10.5430/jha.v6n6p8

\begin{abstract}
Background: Rural and Critical Access Hospitals (CAHs) have a history of operating challenges and closure-conversion threats. The history is reviewed including the supportive public policy provisions and administrative tactics designed to maintain a community's hospital as the hub and access point for health services. Limited research indicates that rural facilities are not strategic in their responses to challenges. A question emerges regarding the enduring nature of operating difficulties for these facilities, i.e., no understanding with explanatory value.

Objective: The author, as the CEO in six rural hospitals designated as turnaround facilities, used inductive participant-observer involvement to identify operating attributes characteristic of these organizations. An objective description of each facility is provided. While implementing a turnaround intervention, fifteen behaviors or outcomes were found to be consistent across all six entities. This information is used to posit factors associated with or accounting for identified performance weaknesses.

Conclusions: It is conceptualization that observed organizational behaviors can be explained as remnants of an agrarian ideology. Such a mindset is focused on preserving the status quo despite challenges that would require strategic positioning of the organization. In addition, emerging studies on community types indicates that follow-up research is needed that assesses the impact of community attributes on rural hospital performance. Also, this study shows that a theory of the rural hospital firm based on neo-classical economics has no explanatory value. Thus, a theory of the firm can be developed that includes behavioral economic principles.
\end{abstract}

Key Words: Rural hospitals, Critical access hospitals, Performance improvement

\section{INTRODUCTION}

Rural America is often characterized as a challenging environment. Wood's Survival of Rural America: Small Victories and Bitter Harvests captures these difficulties and identifies efforts to prevail in the face of such forces. ${ }^{[1]}$ Wood also discusses demographic, economic, and quality-of-life trends characterizing rural life today. Additional rural considerations have focused on the health status and access to care challenges confronting rural residents.
Specifically, this population is viewed as having a poorer health status, higher rate of obesity, and higher mortality rates. This can be attributed to rural populations having lower average incomes than their urban counterparts - factors associated with differing types of employment and education levels. Lower income levels make it more difficult for rural residents to afford health insurance and, therefore, obtain needed care. Additionally, provider shortages and access barriers to care intensify these social determinants of health for rural populations. ${ }^{[2,3]}$

\footnotetext{
*Correspondence: Asa B. Wilson; Email: wilso1ab@cmich.edu; Address: 208 Rowe Hall, Central Michigan University, Mt. Pleasant, MI 48859,
} United States. 
These realities amplify the importance of a rural community's hospital serving as the hub of health services. It has also been posed that the hospital is a symbol of a community's self-sufficiency and agrarian determination. ${ }^{[4]}$ The impact of these service concerns is felt directly by residents as rural care facilities, especially hospitals. Unfortunately, rural hospitals have a history of sustainability challenges despite positive public policy support, recent affiliation tactics, and advances in at-a-distance care technologies; a situation that continues today. Additionally, extensive literature seems not to provide an understanding of the enduring nature of the closure-conversion threat experienced by rural hospitals.

\subsection{Purpose}

The purpose of this paper is to use participant-observer involvement in six rural turnaround hospitals to: (1) define performance characteristic of these entities and (2) discuss performance improvement intervention tactics. An additional purpose is to identify needed follow-up research to address the question about the on-going at risk status of rural and CAHs. An overarching intent is to consider explanatory factors related to the enduring difficulties experienced by rural and CAHs. To these ends, it is important to review the history of rural hospital threats and the supportive public policy responses.

\subsection{Rural hospitals: A history of challenges}

The history of rural hospital difficulties testifies to a collective national and community-level concern for the survival of these facilities. It has been shown that rural hospitals have endured three phases from 1970 forward. ${ }^{[5]}$ The looming specter throughout has been a closure-conversion threat defined as an adverse consequence of collective external factors impacting a facility. Also, the closure alternative is defined as converting to a reconfigured care delivery structure - even though historically neither closure nor conversion has been an acceptable solution to the community and service-area stakeholders.

An augmenting concern was the disproportional closure rate of rural hospital compared to non-rural facilities during 1970 and 1997. The first phase consisted of a policy concern over and research attention to the increasing closure rate of rural facilities; all coupled with a search for key factors associated with closure. It has been argued that this initial phase of research focused on adverse external factors that made it difficult to impossible for closed facilities to have continued. In some respects, the research dialogue characterized hospitals as victims of their rural situation and, to some extent, of public policy amendments associated with prospective reimbursement tactics.

\subsection{Public policy and administrative tactics}

A second phase began with the Balanced Budget Act of 1997 (BBA) as the public policy response to rural hospital distress. Implementing provisions of the BBA resulted in conversion of 1,300 rural facilities to Critical Access Hospital (CAH) status - a hospital located in a rural area, having 25 or fewer acute care beds, providing 24/7 emergency care, and sustaining an average length of stay of 96 hours for acute patients. The rate of rural hospital conversions resulted in a marked reduction of rural hospital closures. In addition, several CAHs have pursued merger or affiliation agreements with urban centers as a tactic to bulwark their sustainability. As of 2008, $42.8 \%$ of rural hospitals have affiliated with larger facilities or systems. To date, limited attention has been given to this trend. Preliminary research indicates this tactic does not significantly enhance the performance of affiliating rural facilities. ${ }^{[6-8]}$

\subsection{Renewed threats - Save Rural Hospital Act of 2015}

However, a third phase has emerged which appears as a reemergence of the original closure-conversion threat. ${ }^{[9]} \mathrm{A}$ recent edition of the New England Journal of Medicine highlighted some of today's compelling challenges unique to rural health services. Specifically, cited is "low volume, declining reimbursement, and staffing challenges" - all in addition to personnel shortfalls, ER physician staffing, and transfer of incident casualties. ${ }^{[10]}$ Providing for the "behavioral and developmental [needs] of rural children" is an intensifying demand - a population that is more likely to encounter mental, behavioral, and developmental disorders (MBDDs) that their urban counterparts. ${ }^{[11]}$ Designing models to meet the obstetrical care needs of rural residents is an intensifying challenge. ${ }^{[12]}$ Confronting high rates of physician turnover in rural facilities is now an established, unavoidable issue. ${ }^{[13]}$

The proposed public policy response this time is H.R. 3225 Save Rural Hospital Act of 2015. ${ }^{[14]}$ The legislation contends that (1) 55 rural hospitals closed from January 2010 until July 8, 2015; (2) currently 283 hospitals are at risk of closing; and (3) such closures would leave 700,000 "without local access to care". In economic terms, H.R. 3225 concludes hospital closures would result in the loss of (1) 50,000 community jobs; (2) 36,000 health care jobs; and (3) $\$ 10$ billion from U.S. GDP. The bill's introduction identifies five other adverse consequences of closing 283 rural hospitals - the negative impact of reduced access to care for rural residents.

To address the closure threat and nine others listed in the legislation, the Act proposes to (1) bulwark existing CAHs and (2) support the creation of an entity - the Community Outpatient Hospital $(\mathrm{COH})$. Specifically, a $\mathrm{COH}$ is a rural facility 
that provides 24-hour emergency room services, outpatient services, and primary care. They would have no inpatient beds, but would be required to maintain an agreement with another facility willing to accept transfer patients requiring hospitalization. That is, a $\mathrm{COH}$ may operate swing beds and observation beds. Also, current CAHs and rural hospitals with 50 beds or less are eligible to convert to $\mathrm{COH}$ status - even such facilities that closed within a 5-year lookback period. Also, CAHs electing to convert to $\mathrm{COH}$ may, in time, pursue their original $\mathrm{CAH}$ status provided they meet the $\mathrm{CAH}$ criteria.

The public policy response, this time, to the closureconversion threat differs from the 1997 BBA because it attempts to align a COH's scope of services and performance with identified community needs. The Act acknowledges the generally accepted challenges of rural care delivery, yet is focused on addressing these difficulties beyond sustaining a full-service community hospital. Doing so avoids the historical pitfalls of the victim outlook and continues the focus on performance, here defined as configuring an organization to meet population-defined needs. As such, it is expected that the results of a community health needs assessment (CHNA) will drive the scope of services provided by a $\mathrm{COH}$, yet within the boundaries specified in the enabling legislation.

1.5 Revisiting contributing factors - Internal v. external Also, despite affiliation tactics and positive public policy provisions, rural health facilities continue to face distress and threats. An enduring question is, "Why are rural and CAHs perpetually distressed facilities?" The most frequently encountered answer emphasizes adverse external factors considered unique to rural America. That is, rural and CAHs are viewed as victims of rural circumstances such that external support is considered the essential antidote - one that ensures or preserves the community's hospital.

\section{Method - PARTicipant-ObSERVER IN- VOLVEMENT}

The following detail explains the type and level of participation in six rural facilities and the information derived from the participant-observer exposure in each organization. I was appointed sequentially as the CEO for each facility over a 13-year period with an average tenure of two years per organization. As the CEO of each hospital, participant-observer involvement provided significant exposure to the dynamics and operating results.

Also, each appointment carried a directive from the governing board to restore the hospital's operating status and enhance its standing in the community. Within the first 60 days of employment, one-on-one interviews were held with department heads, supervisors, Medical Staff members, and 10
Board members. Community leaders were consulted later in the start-up sequence. As a follow-up, a written operations enhancement plan was prepared and submitted to the trustees for review, amendment, and/or approval. Once a plan was endorsed by the governing body, it was progressively implemented according to the specified action steps. As a participant-observer CEO researcher, each facility's responses to the intervention provide valuable organizational insights.

\section{Facilities}

Table 1 provides a side-by-side comparison of the six turnaround facilities according to four key objective attributes common to each facility, e.g., location, facility, governance, and administration. Four of the six facilities were in the Midwest corridor of states having significant agricultural segments. Two facilities were in a Gulf state in locations with diverse community and economic factors - lumber, tourism, energy, and agriculture. Each facility was located in the county seat community with populations ranging from 1,199 to 6,169 . County populations ranged from 2,098 to 14,739 . None of the locations were designated remote or frontier. At the outset, each facility faced significant fiscal distress coupled with a compelling closure-conversion threat.

\section{Findings - Organizational PERFor- MANCE ATTRIBUTES}

An interesting finding is the extent to which the turnaround attributes were consistent across the six organizations. Table 2 summarizes the top operating and performance attributes observed across the six turnaround facilities. These characteristics are not rank ordered in terms of intensity or potency of impact-on-performance. Rather, they are identified as internal factors that individually and collectively had negative consequences for organizational performance. Even though findings from a case study of six rural facilities are not generalizable to a sample or population for rural hospitals, these observations provide insight into internal factors associated with organizational performance. As such, this information indicates needed follow-up research in pursuit of explanatory understanding of such behaviors.

\subsection{Preserving the status quo}

One consequence is that each facility seemingly did not respond as a collective of individuals with rational preferences, especially in the face of outcomes that would prompt an organization to make informed operating adjustments. Instead, it appeared that maintaining the status quo was ascendant over alternative strategic actions. The fact that no facility had a strategic plan or had provisions for an annual planning session is testimony to earlier research that troubled rural facilities tend not to be strategic. ${ }^{[3,15]}$

ISSN 1927-6990 E-ISSN 1927-7008 
Table 1. Side-by-side facility comparisons

\begin{tabular}{|c|c|c|c|}
\hline ATTRIBUTE & FACILITY "A" & FACILITY "B" & FACILITY “C" \\
\hline A. Location & $\begin{array}{l}\text { Far northwest corner of a central plains state. } \\
\text { Community population is less than } 1,788 \text { while } \\
\text { County population is } 2,908 \text {. Area population has } \\
\text { declined consistently by } 2 \% \text { per year over the past } \\
12 \text { years. Facility is located } 24 \text { miles from a larger } \\
\text { full-service community hospital in a town of } \\
8,000 \text {. Largest metropolitan area is } 200 \text { miles west. }\end{array}$ & $\begin{array}{l}\text { East central point of a central plains state } 60 \text { miles } \\
\text { from state's largest metro area. Town's population } \\
\text { is } 6,169 \text { with a County population of } 10,504 \text {. } \\
\text { Facility is } 15 \text { miles from a town of } 32,000 \text { and a } \\
125 \text {-bed full service community hospital. Area has } \\
\text { seen a marked influx of Hispanic residents during } \\
\text { past } 5 \text { years. }\end{array}$ & $\begin{array}{l}\text { Extreme southeast corner of central plains state } 60 \\
\text { miles from town of } 80,000 \text {. Town posts a stable } \\
\text { population of } 4,216 \text { with a county population of } \\
8128 \text {. County has two hospitals within } 25 \text { miles of } \\
\text { each other. Community is } 120 \text { miles from a two } \\
\text { large metro areas of } 300,000 \text { or larger. }\end{array}$ \\
\hline B. Facility & $\begin{array}{l}\text { Combined facility of acute care ( } 24 \text { beds) and } \\
\text { long-term care ( } 50 \text { beds) services. Entity is } \\
\text { supported by a private primary care clinic of } 3 \\
\text { Family Practice physicians and } 1 \text { Nurse } \\
\text { Practitioner. Anesthesia services are provided by } \\
\text { an independent contractor CRNA. A number of } \\
\text { visiting specialty physicians from the metro area } \\
\text { hold clinics on a monthly basis. }\end{array}$ & $\begin{array}{l}\text { Health system consisting of } 1 \text { certified Rural } \\
\text { Health Clinic, } 25 \text { acute care beds and } 40 \text { long-term } \\
\text { care beds. The attached clinic houses } 3 \text { primary } \\
\text { care physicians, } 1 \text { surgeon, } 1 \text { anesthesiologist, and } \\
1 \text { Nurse Practitioner. All providers are employed } \\
\text { by parent corporation. A number of visiting } \\
\text { specialists hold regular clinics. Hospital converted } \\
\text { to Critical Access Hospital (CAH) status. }\end{array}$ & $\begin{array}{l}\text { Facility is a hospital-clinic health system } \\
\text { consisting of } 34 \text { acute beds and } 1 \text { certified Rural } \\
\text { Health Clinic. The Clinic houses } 2 \text { primary care } \\
\text { physicians and } 1 \text { Nurse Practitioner; all of who are } \\
\text { employed by the facility. Community has one } \\
\text { other independent physician and Nurse } \\
\text { Practitioner. Surgical services are provided by an } \\
\text { employed CRNA and itinerant surgeon }\end{array}$ \\
\hline D. Administration & $\begin{array}{l}\text { CEO supervises an Administrative Team - CFO, } \\
\text { Patient Care Executive, and Long-term Care DON. } \\
\text { All staff members are employed by management } \\
\text { company. CEO reports directly to management } \\
\text { company regional vice president. All operating } \\
\text { and planning accountabilities flow to management } \\
\text { company. }\end{array}$ & $\begin{array}{l}\text { CEO reports directly to the corporate Network } \\
\text { Executive who is also a member of the local Board. } \\
\text { The facility has a DON and Controller who reports } \\
\text { to the CEO. The local "senior management" group } \\
\text { has extremely limited authority and functions only } \\
\text { as a pass through body for corporate directives. }\end{array}$ & $\begin{array}{l}\text { CEO is employed by management company and } \\
\text { reports to a corporate vice president. All other staff } \\
\text { members are employed by the local entity. No } \\
\text { administrative group exists. The organizational } \\
\text { chart consists of a CEO with } 25 \text { direct reports. No } \\
\text { local responsibility for budgeting and planning is } \\
\text { in place. }\end{array}$ \\
\hline A. Location & $\begin{array}{l}\text { Located in an isolated southwestern part of a of a } \\
\text { central plains state. The county seat community of } \\
6,161 \text { is in a county of } 7,816 \text {. The largely } \\
\text { agricultural area is dependent upon aquifer } \\
\text { irrigation. Oil and gas reserves have provided a } \\
\text { positive revenue flow for county infrastructure and } \\
\text { services. }\end{array}$ & $\begin{array}{l}\text { Located in a southern point in a gulf state } 110 \text { miles } \\
\text { from a major metropolitan center. The community } \\
\text { of } 5,449 \text { is the county seat of a county of } 14,739 \text {. } \\
\text { The county of } 857 \text { square miles is home to three } \\
\text { communities served by the hospital. The area is } \\
\text { largely agricultural with some oil and gas deposits. }\end{array}$ & $\begin{array}{l}\text { Located on the eastern border of a large } \\
\text { southwestern state. Nearest larger city is } 90 \text { miles } \\
\text { such that the facility is in a small community of } \\
1,199 \text { as the county seat of } 10,834 \text {. The } \\
\text { community is located in a recreational area of the } \\
\text { state know also for an active logging industry. }\end{array}$ \\
\hline B. Facility & $\begin{array}{l}\text { The facility is a 26-bed acute care hospital } \\
\text { supported by a facility-operated rural health clinic } \\
\text { and two independent physician clinics. The current } \\
\text { physical complex emerged following } \\
\text { implementation of a } \$ 24 \text { million } \\
\text { construction-remodel project. }\end{array}$ & $\begin{array}{l}\text { The facility is a } 25 \text {-bed critical access hospital and } \\
\text { a rural health clinic operating as a hospital district. } \\
\text { The district also operates a retail pharmacy, } \\
\text { wellness center, and county-wide EMS service. } \\
\text { The hospital-clinic complex is the result of a } \$ 9 \\
\text { million expansion-renovation project. }\end{array}$ & $\begin{array}{l}\text { Facility is a } 25 \text {-bed critical access hospital and two } \\
\text { free-standing medical clinics. One clinic is a rural } \\
\text { health clinic. }\end{array}$ \\
\hline $\begin{array}{l}\text { C. Ownership - } \\
\text { Governance }\end{array}$ & $\begin{array}{l}\text { Facility is a county-owned facility governed by a } \\
5 \text {-member Board appointed by the County } \\
\text { Commissioners for three-year terms. The Board is } \\
\text { operated under a management service agreement } \\
\text { with a faith-based health system. }\end{array}$ & $\begin{array}{l}\text { The facility operates as a free-standing hospital } \\
\text { district and is subsidized by an annual tax levy. A } \\
\text { 9-member Board is elected by district constituents } \\
\text { on a rotating 2-year cycle. The Board had retained } \\
\text { the services of a management company, yet } \\
\text { discontinued the agreement, electing to manage } \\
\text { operations through an employed CEO. }\end{array}$ & $\begin{array}{l}\text { The facility is a county facility operating as a } \\
\text { hospital districted directed by an elected } \\
\text { six-person board. }\end{array}$ \\
\hline D. Administration & $\begin{array}{l}\text { CEO is employed by the facility, reports to the } \\
\text { Board of Trustees, and coordinates the linkage to } \\
\text { an external management company. }\end{array}$ & $\begin{array}{l}\text { Current CEO and prior interim CEOs have been } \\
\text { employed by the management company and only } \\
\text { recently allowed the agreement to sunset. }\end{array}$ & $\begin{array}{l}\text { The CEO is an employee of the healthcare } \\
\text { management company that leases and operates the } \\
\text { hospital. }\end{array}$ \\
\hline
\end{tabular}

One key finding was the absence of strategic thinking as evidenced by a willingness to allow the facility to be buffeted by negative externals. It was as if maintaining the status quo was a high calling or was a strategic posture necessary to preserve the hospital. In addition, each facility displayed an initial reluctance to embrace operating enhancements, at least until it was demonstrated that the intervention was not a threat to the facility or its personnel. The same sense of threat was expressed by residents, especially during the early months of implementation. This final observation stimulated considera- tion of the extent to which community dynamics could be a factor associated with facility performance - something that has received limited research attention.

\subsection{Framing an intervention}

A critical lesson was understanding the importance of the way in which a turnaround intervention is framed, created, and introduced. A turnaround is readily characterized as a corrective force intended to reverse individual or collective behaviors deemed counterproductive and detrimental to or- 
ganizational performance. Targeted corrective actions are perceived as negative and frequently provoke resistance or collective opposition. Also, a turnaround is typically considered a time-limited thrust that will be discontinued once the failure-risk attributes are eased or resolved. This dynamic is typical even after the governing body has endorse a turnaround plan.

Table 2. Characteristics of a turnaround facility

\begin{tabular}{ll}
\hline No. & Characteristic \\
\hline 1. & Limited definition of and respect for organizational boundaries, \\
2. & Poorly delineated lines of authority and leadership responsibility. \\
3. & Governance by "oral tradition" instead of well-defined policies. \\
4. & Marginal Medical Staff leadership \\
5. & Proliferation of non-essential work coupled with higher than needed staff levels. \\
6. & Significantly weakened capacity to plan, organize, and implement strategies. \\
7. & Progressive decline in statistical and financial performance. \\
8. & No apparent internal initiatives or plans to correct the performance outcomes. \\
9. & Former leadership heralded as a God-send or scapegoat. \\
10. & Many activities are self-directed, not organizationally determined. \\
11. & Marketing, public relations, and advertising are haphazard plus expensive. \\
12. & Cluster of avoided and/or unresolved personnel difficulties persist. \\
13. & Causes of problems are defined as external to the organization - Reactionary. \\
14. & Information flow is inconsistent, weak, and diffuse. \\
15. & Documentation of transactions is limited and poorly executed. \\
\hline
\end{tabular}

As an alternative, such an intervention can be framed as a type of start-up or rebuilding of the facility. Doing so limits the negative perception of an "intrusion" identified as a turnaround. A start-up strategy is anchored in a positive vision intended of an emerging organization and is focused on the essential mission, goals, and processes.

Even though each governing board endorsed the proposed operations enhancement plan and the implications of the intervention, two facilities opted not to continue executing the plan. Instead, the focus shifted to minimizing internal distress over performance improvement expectations, especially in clinical and financial areas.

Findings from the turnaround facilities provide an intensified view of failure dynamics and organizational responses to focused performance improvement interventions. Even though the observed attributes summarized in Table 2 are consistent across the six facilities, this information has limited explanatory value. As such, this study is a foundation for considering more specific factors contributing to the unproductive organizational dynamics and adverse performance outcomes. This situation creates opportunities for future research focused on enhancing an explanatory understanding of the organizational behavior of rural facilities, especially hospitals.

\subsection{Hypothesized rural living and outlook}

The observed organizational behaviors occurring across six facilities suggested that a collective outlook or mindset was operating - one closely associated with the behaviors identi- fied in Table 2. From an explanatory perspective, Wilson ${ }^{[3]}$ has proposed that such rural organizational behaviors are remnants of an agrarian ideology. In doing so, an agrarian outlook was deconstructed into five themes - Community Centricity, Relationship Ascendency, Longevity Exemption, Regulatory Optionality, and Performance Independence. Each theme, in turn, was linked to a cluster of behaviors observed in rural health facilities. Each theme and its behaviors were discussed as remnants of agrarian thinking and in terms of their impact on organizational performance. At this research stage, it is reasonable to hypothesize that a collective mindset can account for organizational behaviors as a significant internal factor related to organizational performance.

\section{Discussion}

This section considers an intrinsic dynamic of these six facilities and lessons learned from these turnaround interventions. Within the matrix of concerns expressed for rural health services, the rural hospital has consistently identified as the unwitting beneficiary of the adversities of rural care delivery. The consistency and intensity of this position reinforces the hospital-as-victim view such that there is a link between such a perspective and the provisions of the 1997 BBA.

\subsection{Strategic positioning}

Against the concern for the rural hospital stands one thread, e.g., "Are rural hospitals strategic?" ${ }^{[15-18]}$ Within this thread, strategic is defined as the capacity of a rural hospital to amend its operations in order to prevail within the emerging external challenges. These studies argued that rural hospitals are not strategic and that stakeholders simultaneously have an obligation with an opportunity to meet these rural challenges, e.g.,

"There is a body of experience that demonstrates that rural communities can successfully define an appropriate mix of health services, address critical responsibility for the future of this essential element of community, and bring the community into the loop to take responsibility for the future of this essential element of community.",[17]

Unfortunately, this section does not find that this thread was developed in subsequent research, or policy advances, or operating amendments. Rather, rural hospitals were largely rescued by the provisions of the BBA in 1997 and following.

\subsection{Follow-up research opportunities}

Findings from this participant-observer involvement in six rural hospitals has also identified specific follow-up research opportunities. Both research tracks will pursue further understanding of key factors associated with or explanatory of rural hospital performance. This effort will be accomplished 
in two areas: (1) identifying and assessing the impact of community typology on facility performance and (2) building a behavioral economic theory of the rural hospital firm. The overarching assumption is that each area has received limited research attention and that enhanced quantitative understanding has policy, governance, administrative, and performance value for these entities and their service areas.

\subsubsection{Rural community typology}

Case study findings suggest that community style, dynamic, or typology differ from community - force that has a direct impact on facility performance. Also, there is a literature confirming the reality if community types and quantitative tools for identifying clusters of types. ${ }^{[19-21]}$ That is, it would be possible to create statistical clusters of rural communities based on a set of attributes. In turn, this information makes it possible to assess the relationship between community types and organizational performance. For example, Liu et al. have researched the impact of patient and community characteristics on the rate at which patients bypass local primary care services. ${ }^{[22]}$ However, limited attention has been given to the community as a factor impacting the performance of rural health facilities.

Also, Herrin et al. have shown that community factors are associated with the rate of hospital readmissions. ${ }^{[23]}$ The authors conclude that:

“... this study is one of the most thorough looks to date at how hospital readmission rates are explained by community-level factors. The evidence shows that after accounting for patientrisk factors ... and community socioeconomic factors ... as well as accounting for hospital characteristics and location, a substantial amount of the variation in readmission rates is explained by local health-system characteristics ... We found that nearly 60 percent of the variation in ... readmission rates is explained by the county where the hospital is located, and that county measures, including socioeconomic status, physician mix, and nursing home quality, explaining nearly half of this county-level variation."

In addition, the authors discussed policy and performance improvement opportunities for hospitals given the explanatory power resulting from identifying community variables impacting facility performance.

More recently, a Critical Access Hospital Community Apgar Questionnaire (CAH CAQ) has been developed using 50 community attributes considered supportive of or hindrances to successful physician recruitment. ${ }^{[24]}$ The scope of community factor domains (Geographic Class, Facility and Community, Medical, Scope of Practice, and Economic) and the 60 domain specific factors renders the questionnaire a comprehensive community assessment tool. As such the Published by Sciedu Press
CAQ creates a research opportunity focused on community factors of facility performance.

The research opportunity now is to identify the key aspects of a community that are associated with facility performance. A first step is to identify the community-facility attributes leading to clusters of community types. A second step is to correlate hospital performance with community types. This can be done: (1) concurrently and (2) retrospectively. Concurrent assessment provides a limited point-in-time snapshot of performance variance accounted for by community factors. Retrospective analysis using a 5-year lookback review provides trend information for sustaining hospitals as well as for closed or converted facilities. Therefore, pursuing an expanded understanding of factors linked to hospital performance is an essential adjunct to policy, governance, and administrative support for rural health service stakeholders. At this point, there is supportive evidence indicating to posit that the community in which a facility is embedded is a factor associated with facility performance.

\subsubsection{Theory of the rural health firm}

For all intents and purposes, there seems not to be an articulated theory of the firm - a perspective that provides explanatory strength regarding the organizational behavior of rural health facilities, especially hospitals. At this point in our understanding, the observer behaviors of these entities indicate what such facilities are not. For example, the behavior of a rural hospital is not readily explained by principles of neo-classical economics. They are not: (1) strategic in response to externals; ${ }^{[15,16]}$ (2) technically efficient; ${ }^{[25]}$ (3) profit maximizers; (4) utility maximizers; (5) driven by rational preferences. Thus, there is no economic theory from which to predict the behavior of a rural health facility or help these facilities sustain themselves or adjust to challenges accordingly.

\section{Conclusions}

Limited participant-observer case study findings in six rural hospitals posting significant overall performance shortfalls is consistent with research indicating that such facilities are not strategic. In addition, the consistency of these observations confirms that there is still limited explanatory understanding of the persistent nature of closure-conversion threats confronting these facilities. This situation, in turn, creates research opportunities to assess community factors associated with hospital performance. Furthermore, the time has come to consider behavioral economic elements in the form of a theory of the rural hospital firm - a conceptual starting point for building and testing a theory of the rural health firm. ${ }^{[26]}$

\section{CONFLiCTS OF INTEREST Disclosure}

The authors declare they have no conflicts of interest. 


\section{REFERENCES}

[1] Wood RE. Survival of rural America: Small victories and bitter harvests. Lawrence: University Press of Kansas; 2008.

[2] Bennett KJ, Olatosi B, Probst JC. Health Disparities: A rural-urban chartbook. Columbia: South Carolina Rural Health Research Center; 2008 .

[3] Hartley D. Rural health disparities, population health, and rural culture. Am J Public Health. 2004; 94(10): 1675-1677. PMid: 15451729. https://doi.org/10.2105/AJPH.94.10.1675

[4] Wilson AB. Agrarian ideology remnants and rural healthcare organizational behavior: Observations and research opportunities. J Res Health Sci. 2016; 1(2): 125-145. https ://doi .org/10.22158/r hs. v1n2p125

[5] Wilson AB, Kerr BJ, Bastian NS, et al. From surviving to community benefit: A proposed rural health services research agenda. J Hosp Admin. 2014; 3(5): 105-114. https://doi.org/10.5430/jha. v3n5p104

[6] Herald LR, Carroll NW. Interorganizational relationship trends of Critical Access Hospital. J Rural Health. 2016; 32(1): 44-55. https://doi.org/10.1111/jrh.12131

[7] Noles MJ, Reiter KL, Boortz-Marx J, et al. Rural hospital mergers and acquisitions: Which hospital are being acquired and how are they performing afterward? J Healthc Manag. 2015; 60(6): 395-407. PMid: 26720983.

[8] Swofford MD. Rural hospital system affiliations and their effects on hospital economic performance, 2004-2008. Doctoral dissertation, Virginia Commonwealth University; 2011.

[9] Kaufman BG, Thomas SR, Randolph RK, et al. The rising rate of rural hospital closures. J Rural Health. 2016; 32(1): 35-43. PMid: 26171848.

[10] Hartman M, Graziadei J. Thirty miles at sea - Providing consistent care in an inconsistent environment. N Engl J Med. 2017; 376(14): 1306-1307. PMid: 28379807. https ://doi.org/10.1056/NEJM p1701449

[11] Kelleher KJ, Gardner W. Out of sight, out of mind - Behavioral and developmental care for rural children. N Engl J Med. 2017; 376(14): 1301-1303. PMid: 28301297. https ://doi.org/10.1056/NEJM p1700713

[12] Mann S, McKay K, Gardner W. The maternal health compact. N Engl J Med. 2017; 376(14): 1304-1305. PMid: 28379803. https : //doi.org/10.1056/NEJMp1700485

[13] Kovich H. And how long will you be staying, Doctor? N Engl J Med. 2917; 376(14): 1308-1309.
[14] Save Rural Hospitals Act of 2015. H.R. 3225, 114 ${ }^{\text {th }}$ Cong. 2015.

[15] Trinh HQ. Are rural hospitals "strategic"? Health Care Manage Rev. 1999; 24(3): 42-54. PMid: 10463106

[16] Trinh HQ, Begun JW. Strategic adaptation of US rural hospitals during an era of limited financial resources: A longitudinal study, 1983 to 1993 . Health Care Manag Sci. 1999; 2(1): 43-52. https : //doi.org/10.1023/A:1019063123037

[17] Admundson B. Myth and reality in the rural health service crisis: Facing up to community responsibility. J Rural Health. 1993; 9(2): 176-187. PMid: 10128157.

[18] Mick SS, Morlock LL, Salkever D, et al. Strategic activity and financial performances of U.S. rural hospitals: A national study, 1983 to 1988. J Rural Health. 1994; 10(3): 150-167. PMid: 10138031. https://doi.org/10.1111/j.1748-0361.1994.tb00225.x

[19] Crow GP, Allan G. Community types, community typologies and community time. Time \& Society. 1995; 4(2): 147-166. https: //doi.org/10.1177/0961463X95004002001

[20] Luke DA. Getting the big picture in community science: Methods that capture context. Am J Community Psychol. 2005; 35(3-4): 185200. PMid: 15909794. https://doi.org/10.1007/s10464-0 05-3397-z

[21] Altaweel M, Virapongse A, Griffith D, et al. A typology for complex social-ecological systems in mountain communities. Sustainability: SSPP. 2015; 11(2): 1-13.

[22] Liu JJ, Bellamy G, Barnet B, et al. Bypass of local primary care in rural counties: Effect of patient and community characteristics. Ann Fam Med. 2008; 6(2): 124-130. PMid: 18332404. https : //doi.org/10.1370/afm.794

[23] Herrin J, St AJ, Kenward K, et al. Community factors and hospital readmission rates. Health Serv Res. 2015; 50: 20-39. PMid: 24712374.

[24] Baker ET, Schmitz D, Marshall J, et al. What factors do critical access hospital trustee/board members believe are important to recruitment of physicians and do they differ from hospital administrators and physicians. J Hosp Admin. 2017; 6(3): 33-40. https://doi.org/10.5430/jha.v6n3p33

[25] Wilson AB. A rural health care research bibliography and narrative: Articulating an applied research agenda. Unpublished manuscript, Division of Health Administration, Central Michigan University; 2013.

[26] Speckbacher G. The economics of performance management of nonprofit organizations. Nonprofit Manag \& Leadersh. 2003; 13(3): $267-$ 281. https://doi.org/10.1002/nml.15 